УДК 376

\title{
О РИСКАХ ОРГАНИЗАЦИИ И РЕАЛИЗАЦИИ ИНКЛЮЗИВНОГО ПРОФЕССИОНАЛЬНОГО ОБУЧЕНИЯ
}

\author{
Солдатов Дмитрий Вячеславович \\ кандидат психологических наук, доцент кафедры \\ психологии и социальной педагогики \\ Петрова Елена Александровна \\ кандидат психологических наук, доцент кафедры \\ психологии и социальной педагогики \\ декан психолого-педагогического факультета \\ ГОУ ВО МО «Государственный \\ гуманитарно-технологический университет»
}

\begin{abstract}
Аннотация. В статье представлен анализ противоречий, рисков, которые возникают при организации и реализации инклюзивного (интегрированного) обучения лиц с инвалидностью и ограниченными возможностями здоровья в организациях профессионального обучения (колледжах) или в высшей школе (ВУЗах). Авторы высказывают свое мнение относительно вероятности возникновения рисков и некоторых мер и условий, снижающих риски возникновения негативных явлений в условиях образовательной инклюзии.
\end{abstract}

Ключевые слова: инвалидность, ограниченные возможности здоровья, инклюзивное обучение, противоречия, риски в обучении.

\section{ON THE RISKS OF ORGANIZATION AND IMPLEMENTATION OF THE INCLUSIVE PROFESSIONAL TRAINING}

\section{Soldatov Dmitry Petrova Elena}

\begin{abstract}
The article presents an analysis of the contradictions, risks that arise in the organization and implementation of inclusive (integrated) education of persons with disabilities and disabilities in vocational training organizations (colleges) or in higher education (universities). The authors express their opinion on
\end{abstract}




\section{МОДЕРНИЗАЦИЯ СОВРЕМЕННОГО ОБРАЗОВАНИЯ: АНАЛИЗ ОПЫТА И ТЕНДЕНЦИЙ}

the likelihood of risks and some measures and conditions that reduce the risks of negative phenomena in the context of educational inclusion.

Key words: disability, disabilities, inclusive learning, contradictions, risks in learning.

Анализ рисков реализации системы работы образовательных организаций в условиях организации инклюзивного профессионального образования начнем с того, что в современной психолого-педагогической литературе нет исчерпывающего описания, оценки вероятных и реальных рисков. Анализ опыта и оценка перспектив организации инклюзивного обучения «лиц с ограниченными возможностями здоровья» (ЛОВЗ) имеет в настоящее время фрагментарный и во многом субъективный характер. Между тем понятно, насколько важно предвидеть и минимизировать риски и неизбежные негативные последствия любых педагогических инициатив, экспериментов $[1,2,3,5]$.

Не претендуя на исчерпывающий анализ проблем организации и реализации интегрированных форм профессионального обучения, остановимся лишь на некоторых существующих при этом противоречиях, например:

- между темпом обучения ЛОВЗ и обучающимися без ОВЗ;

- между необходимостью создания специальных условий для обучающихся ЛОВ3 и зачастую имеющей место объективной недостаточностью этих условий в конкретной образовательной ситуации;

- между необходимостью опираться в обучении на жизненный опыт и дефицит жизненного опыта, жизненных представлений ЛОВЗ;

- между требованиями учебной активности от субъектов обучения, особенно в высшей школе и пониженной учебной активностью многих ЛОВ3;

- между образовательными потребностями обучающихся без ОВ3 и образовательными потребностями обучающихся с ЛОВ3;

- между необходимостью трансформировать процесс обучения для ЛОВ3 и неготовностью педагога к такой трансформации (когда педагог не понимает необходимость такого изменения, или не знает, как изменить процесс обучения, чтобы привести его в соответствие с потребностями ЛОВЗ и существующими нормативными документами, традициями, ожиданиями);

- между необходимостью в сопровождении специалистов процесса инклюзивного обучения и отсутствием (дефицитом) такого сопровождения. 


\section{МОДЕРНИЗАЦИЯ СОВРЕМЕННОГО ОБРАЗОВАНИЯ: АНАЛИЗ ОПЫТА И ТЕНДЕНЦИЙ}

Конечно, перечень противоречий можно продолжить. К существующим противоречиям, сопровождающим организацию и реализацию инклюзивного обучения, следует относиться как к естественным и закономерным трудностями реализации любой педагогической новации. Противоречия являются диалектическими по своей природе, преодолимыми, они не просто препятствия на пути его осуществления, а скорее педагогические и психологические задачи.

В связи со сложностью организации, реализации и противоречивостью инклюзивное обучение ЛОВЗ сопряжено с определенными рисками $[1,2,4,5]$. Различают риски реализации инклюзивного образования и риски нереализации, т.е. бездействия. Приведем лишь некоторые примеры тех и других.

К рискам организации и реализации инклюзивного обучения относят следующие:

- «гипертрофированная» инклюзия, акцентированная на ограничениях и сложностях обучения и социализации детей с ОВ3, при которой осуществляется чрезмерная, инфантилизирующая забота о детях с ОВ3;

- «нетрудоустроенность» ЛОВЗ по окончании профессионального обучения и низкая конкурентоспособность выпускников профессиональных образовательных организаций с ОВ3;

- ухудшение состояний здоровья обучающихся инвалидов и ЛОВЗ в ходе обучения;

- низкие результаты профессиональной подготовки у закончивших обучение ЛОВ3, отсутствие или недостаточная сформированность у них компетенций (социальных, учебных, профессиональных);

- формирование в процессе обучения понимания своего несоответствия требованиям профессиональной деятельности;

- разочарование в выбранной для обучения профессии;

- появление деформаций характера и личности обучающихся ЛОВЗ (низкая самооценка, повышенная тревожность, озлобленность, «выученная беспомощность» и др.);

- появление и закрепление у студентов с ОВ3 девиантных (деструктивных) форм поведения и общения (замкнутость, пониженная активность, истеричность, агрессивность, вандализм, употребление ПАВ и др.); 


\section{МОДЕРНИЗАЦИЯ СОВРЕМЕННОГО ОБРАЗОВАНИЯ: АНАЛИЗ ОПЫТА И ТЕНДЕНЦИЙ}

- инвалидизирующее воспитание: формирование в обучении психологической установки на неспособность, на пассивное ожидание помощи и активности со стороны;

- возникновение конфликтов, неприязненных отношений, негативных оценок, обвинений между обучающимися с OB3 и обучающимися, не имеющими ОВ3;

- возникновение буллинга в образовательной организации и приобретение ЛОВ3 негативного опыта межличностных отношений в обучении;

- обособление ЛОВ3 в образовательной организации: возникновение «закрытых» групп обучающихся с ОВ3;

- недостаточное внимание к вопросам обучения лиц без ОВ3, падение качества обучения, понижение уровня требований к результатам обучения в общеобразовательной организации в целом;

- внутриличностный конфликт у педагогических работников образовательной организации, связанный с психологическими противоречиями: с одной стороны, их желанием помочь в обучении и профессионализации ЛОВ3, а с другой стороны, в их неподготовленности, неспособности создать надлежащие условия, невладение соответствующими психолого-педагогическими технологиями;

- негативные психические состояния педагогов, реализующих инклюзивное обучение ЛОВЗ, возникновение синдромов эмоционального и иного «выгорания» педагогов, требующих своевременной психотерапевтической помощи;

- возникновение у педагогов образовательной организации ощущения «непосильности» решения задач организации результативного инклюзивного обучения, переживание состояния собственного педагогического «бессилия», того, что они являются «заложниками» чьих-то образовательных амбиций.

Существуют также и риски нереализации, недостаточности действий по реализации инклюзивного обучения:

- так называемая «дикая», «стихийная», неуправляемая инклюзия обучение ЛОВЗ в общеобразовательном учреждении в соответствии с Конституцией РФ и Законом об образовании - в образовательных учреждениях по выбору родителей, по месту жительства, но без создания специальных условий, т.е. без учета их возможностей и особых образовательных потребностей; 


\section{МОДЕРНИЗАЦИЯ СОВРЕМЕННОГО ОБРАЗОВАНИЯ: АНАЛИЗ ОПЫТА И ТЕНДЕНЦИЙ}

- неадекватное, неполноценное познавательное и личностное развитие детей с ОВ3 в условиях доминирования эксклюзии, сегрегации (надомное обучение, дистанционное обучение, интегрированное обучение в «особых» группах);

- невозможность самореализации (профессионализации) в обществе в настоящем и будущем; ощущение своей ненужности обучающимися с OB3;

- неудовлетворенность ЛОВЗ и их родителей условиями и технологиями обучения в образовательной организации.

Нам важно на примере указанных противоречий и обозначенных рисков проиллюстрировать, что мы не в состоянии в каждый момент времени, по отношению к каждому ЛОВЗ дать объективную оценку реальности рисков организуемого нами обучения, дать достаточно обоснованный прогноз качества образования и качества профессиональной подготовки всех участников инклюзивного обучения как нормотипичных обучающихся, так и обучающихся с инвалидностью и ОВЗ. В настоящее время не получили объективной научной оценки ни вероятности реализации негативных последствий инклюзивного обучения, ни условия профилактики рисков и их последствий.

Подводя итог краткому анализу возможных рисков организации профессионального обучения ЛОВЗ, следует сказать, что комплексная оценка реальности и степени опасности реализации инклюзивного обучения является масштабной научно-практической задачей ближайшего времени, в решении которой должны будут принять участие специалисты разных научных направлений и уровня, а также широкая общественность.

Профессиональное обучение инвалидов и ЛОВЗ, к сожалению, не всегда эффективно и результативно, не всегда соответствует стандартам и целям обучения. Среди прочих причин это достаточно часто связано с незрелостью учебной мотивации и мотивации труда самих инвалидов и ЛОВЗ. По нашему мнению, учить профессии имеет смысл лишь тех инвалидов и ЛОВЗ, которые действительно хотят учиться, развиваться, работать. В противном случае, обучение и попытки их трудоустроить (когда другие люди пытаются их трудоустроить) заканчиваются плачевно: к реальной трудовой деятельности многие из них не готовы, работать не хотят и, скорее всего, не будут.

Инклюзивное обучение нужно выстраивать тогда, когда обучающийся не только имеет желание, но и реальную готовность, способность жить и учиться по тем же правилам, традициям, что и все остальные обучающиеся. 
Если же мы создаем вокруг ребенка с ОВЗ слишком специфические условия, в которых он имеет больше, чем остальные обучающиеся прав, привилегий, преимуществ, внимания и снисхождения со стороны педагога, то мы организуем не инклюзивное, а эксклюзивное обучение.

Студент-инвалид, или имеющий ОВ3, должен, прежде всего, сам прилагать усилия, чтобы соответствовать ожиданиям, требованиям, во всем на равных (но по-своему) принимать участие в едином образовательном процессе, активно и самостоятельно адаптироваться к условиям общего образования. Это не исключает оказания ему специальной помощи и создания специальных условий, например, в виде использования технических средств и вариативных технологий обучения. В основе инклюзивных процессов должны стоять не просто желания родителей, не их амбиции и стремление требовать «особых условий» (программ, технологий, занятий, форм и т.д.), а естественное желание обучающегося с ОВЗ самореализоваться, доказать свое право и способность быть, жить, учиться «на равных». Принцип равенства прав предполагает и равенство способностей достойно этими правами воспользоваться.

Глобальная задача образовательной организации состоит не просто в учете и приспособлении процесса обучения к особенностям студентов с ОВ3 и инвалидностью, а том, чтобы максимально активизировать их внутренний потенциал, порою скрытые ресурсы для развития и обучения. Важно создать условия стимулирования адаптации, стремления студентов с ОВ3 к саморазвитию, к напряженному самоизменению в условиях профессионализации. Без таких внутренних изменений немыслимо профессиональное самосознание и профессиональная идентификация. Без условий стимулирования личностного потенциала, трансформации личности любой студент - с ОВ3 или без них - не сможет стать понастоящему профессионалом и начать самостоятельно работать даже после получения диплома установленного образца. 


\section{Список литературы}

1. Алехина С.В. Инклюзивное образование: от политики к практике // Психологическая наука и образование. 2016. Том 21. № 1. С. 136-145. doi:10.17759/pse.2016210112. URL: https://psyjournals.ru/psyedu/2016/n1/ alekhina.shtml (дата обращения: 08.10.2021)

2. Гончарова В.Г., Подопригора В.Г. Управление рисками в системе профессионального инклюзивного образования как элемент менеджмента качества. // Специальное образование. 2015. № 3. С. 138-148. URL: https://cyberleninka.ru/article/n/upravlenie-riskami-v-sisteme-professionalnogoinklyuzivnogo-obrazovaniya-kak-element-menedzhmenta-kachestva (дата обращения: 08.10.2021).

3. Ливенцева Н.А. Проблемы практической реализации инклюзивного образования в США и странах Европы [Электронный ресурс] // Современная зарубежная психология. 2012. Том 1. № 1. С. 20-29. URL: https:// psyjournals.ru/jmfp/2012/n1/50095.shtml (дата обращения: 08.10.2021).

4. Назарова Н.М. Системные риски развития инклюзивного и специального образования в современных условиях // Специальное образование. 2012. № 3. С. 6-12.

5. Хуснутдинова М.Р. Риски инклюзивного образования. // Образование и наука. 2017; (3) : 26-46. URL: https://doi.org/10.17853/19945639-2017-3-26-46 (дата обращения: 08.10.2021).

(С Д.В. Солдатов, Е.А. Петрова, 2021 